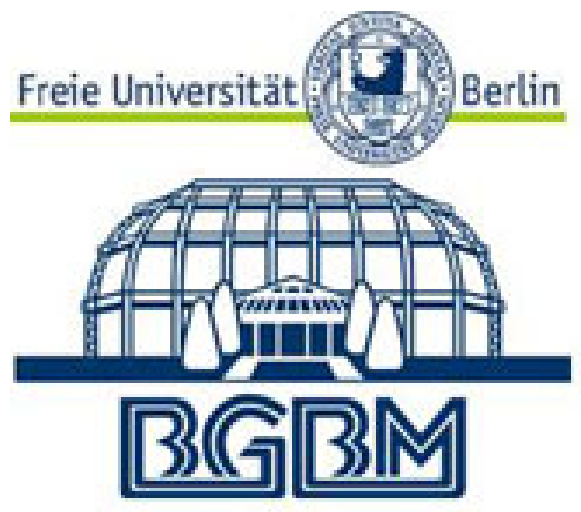

Beschreibung eines neuen Sedums aus Mexiko (S. Adolphi)

Author(s): Raymond Hamet

Source: Notizblatt des Königl. botanischen Gartens und Museums zu Berlin, Bd. 5, Nr. 49 (Jun. 27, 1912), pp. 277-278

Published by: Botanischer Garten und Botanisches Museum, Berlin-Dahlem

Stable URL: http://www.jstor.org/stable/3994442

Accessed: 14/06/2014 06:11

Your use of the JSTOR archive indicates your acceptance of the Terms \& Conditions of Use, available at http://www.jstor.org/page/info/about/policies/terms.jsp

JSTOR is a not-for-profit service that helps scholars, researchers, and students discover, use, and build upon a wide range of content in a trusted digital archive. We use information technology and tools to increase productivity and facilitate new forms of scholarship. For more information about JSTOR, please contact support@jstor.org. 


\section{Beschreibung eines neuen Sedums aus Mexiko (S. Adolphi).}

Von

\section{Raymond Hamet.}

Sedum Adolphi ${ }^{1}$ ) Raymond Hamet n. sp. Planta perennis, storiles caules edens. Radices fibratae? Caules floriferi erecti, robusti, ramosi, glabri. Folia alterna, sessilia, infra insertionem in calcar non producta, integra, acuta, longiora quam latiora; caulium sterilium folia obovato-lanceolata; caulium floriferorum folia late obovata. Inflorescentia corymbiformis, satis densa. Pedicelli quam calyx longiores, glabri. Flores satis numerosi. Calyx glaber, segmentis 5, quam tubus paulo brevioribus vel paulo longioribus, infra insertionen in calcar non productis, deltoidei-subsemi-orbicularibus, marginibus integris, apice apiculatis, tam longis quam latis vel paulo longioribus quam latioribus. Corolla glabra, quam calyx longior, segmentis 5, quam tubus multo longioribus, ovato-lanceolatis, marginibus integris, apice aristatis, arista petali apicem superante, longioribus quam latioribus. Stamina 10, glabra; filamenta oppositipetala infra corollae medium inserta; antherae corollae medium superantes. Carpella 5, multiovulata, glabra, in stylos quam carpella paulo breviores attenuata. Squamae 5, late obovato-subquadratae, apice subbilobatae, lobis leviter crenatis, paulo latiores quam longiores. Folliculi 5, multiseminati, erecti, lateribus internis non gibbosis. Semina ...

Planta . . cm longa. Caulium sterilium folia $27-29 \mathrm{~mm}$ longa, 13,50-14 mm lata. Caulium floriferorum folia $18 \mathrm{~mm}$ longa, $12 \mathrm{~mm}$ lata. Inflorescentia $30 \mathrm{~mm}$ longa, $40 \mathrm{~mm}$ lata. Pedicelli $8,50-12 \mathrm{~mm}$ longi. Calycis pars concreta $1,10-1,20 \mathrm{~mm}$ longa; pars libera 0,75 bis $1,60 \mathrm{~mm}$ longa, $0,75-1,20 \mathrm{~mm}$ lata. Corollae pars concreta $0,60 \mathrm{~mm}$ longa; pars libera $6 \mathrm{~mm}$ longa, 2,30 mm lata. Staminum alternipetalorum filamentorum pars concreta $0,60 \mathrm{~mm}$ longa; pars libera $5 \mathrm{~mm}$ longa, $0,45 \mathrm{~mm}$ lata. Staminum oppositipetalorum filamentorum pars concreta 1,20 mm longa; pars libera $3,05 \mathrm{~mm}$ longa, 0,40 mm lata. Antherae $1 \mathrm{~mm}$ longae, $0,85 \mathrm{~mm}$ latae. Carpellorum pars concreta $1 \mathrm{~mm}$

1) Veneratione ductus, speciei pulchrae et distinctissimae, cel. Prof. Adolphi Engler, musei botanici Berolinensis directori, nomen imposui. 
longa; pars libera $2,80 \mathrm{~mm}$ longa. Styli $2,20 \mathrm{~mm}$ longi. Squamae $0,35-0,40 \mathrm{~mm}$ longae, $0,50-0,60 \mathrm{~mm}$ latae.

Im Bot. Garten zu Berlin-Dahlem kultiviert, aus Samen, welche in Mexiko von Purpus gesammelt wurden.

Obs. Haec species, quamvis Sedo allantoidei $\operatorname{Ros}^{\mathrm{t}}$ ) et Sedo Treleasei $\mathrm{Rose}^{2}$ ) valde affinis sit, distinctissima est,

a S. allantoide: $1^{0}$ foliis obovato-lanceolatis vel late obovatis, acutis et non teretibus, lineari-obovatis, obtusissimis; $2^{0}$ sepalis deltoidei-subsemiorbicularibus, apiculatis, et $n$ on ovatis vel ovato-oblongis, acutis; $3^{0}$ petalis ovato-lanceolatis, aristatis, arista petali apicem superante, et non oblongo-lanceolatis, mucronatis, mucrone petali apicem non superante; $4^{0}$ folliculis lateribus internis non gibbosis; $5^{0}$ squamis subbilobatis, lobis leviter crenatis, paulo latioribus quam longioribus et non obtusissimis, paulo longioribus quam latioribus;

a S. Treleasei: $1^{0}$ pedicellis calyce longioribus, et non brevioribus; $2^{0}$ sepalis deltoidei-subsemiorbicularibus, apiculatis, tam longis quam latis vel paulo longioribus quam latioribus, et no n obovato-sublinearibus, acutis, valde longioribus, quam latioribus, $3^{0}$ petalis ovata-lanceolatis, et non obovatis; $4^{9}$ squamis subbilobatis, lobis leviter crenatis, paulo latioribus quam longioribus et non leviter retusis, paulo longioribus quam latioribus.

1) J. N. Rose, Five n. sp. of Crassulaceae from Mexico, in Contr. U. S. Nat. Herb., t. XII, pars 10, p. 440 et tab. LXXIX (1909).

$\left.{ }^{2}\right)$ J. N. Rose, Stud. of Mexic. a. Centr. Amer. pl., in Contr. U. S. Nat. Herb., t. XIII, pars 9, p. 300 et 301 et tab. 60 (1911). 